\title{
LAS MINORÍAS LINGÜÍSTICAS EN EL ORDENAMIENTO ITALIANO: DESARROLLOS NORMATIVOS RECIENTES
}

\author{
VALERIA PIERGIGLI \\ Profesora Extraordinaria de Derecho Constitucional \\ Facultad de Derecho, Universidad de Siena
}




\section{SUMARIO}

1. INTRODUCCIÓN. 2. El AUXILIO DEL DERECHO INTERNACIONAL Y REgIONAL PARA LA DEFINICIÓN DE UN ESTATUTO JURÍDICO DE LAS MINORIAS LINGÜISTICAS O DE LAS LENGUAS MINORITARIAS. 3. El arTículo 6 dE LA CONSTITUCIÓN ITALIANA Y LA INTERPRETACIÓN DEL TRIBUNAL CONSTITUCIONAL ITALIANO: LA DISTINCIÓN ENTRE MINORIAS LINGÜÍSTICAS RECONOCIDAS Y NO RECONOCIDAS. 4. LA LEY 482/1999 Y LA RECIENTE EVOLUCIÓN DE LA NORMATIVA ESTATAL DE TUTELA DE LAS MINORIAS LINGÜISTICAS. 5. LAS INICIATIVAS DE LAS AUTONOMIAS TERRITORIALES ENTRE PROMOCIÓN DE LOS PATRIMONIOS CULTURALES Y GARANTÍA DE LOS USOS PÚBLICOS DE LAS LENGUAS MINORITARIAS. 6. CONCLUSIONES: RIESGOS E IMPLICACIONES CONEXAS AL PROGRESIVO REFORZAMIENTO DE LA TUTELA DE LAS MINORÍAS. 


\title{
LAS MINORÍAS LINGÜÍSTICAS EN EL ORDENAMIENTO ITALIANO: DESARROLLOS NORMATIVOS RECIENTES*
}

POR

\author{
VALERIA PIERGIGLI \\ Profesora Extraordinaria de Derecho Constitucional \\ Facultad de Derecho, Universidad de Siena
}

1. La garantía de los derechos de los pertenecientes a las minorías lingüísticas y la conservación de los patrimonios lingüísticos minoritarios en el ordenamiento italiano constituyen, al menos desde la entrada en vigor de la Constitución Italiana ( $\mathrm{Cl}$ en lo sucesivo); temas sobre los cuales no se ha dejado nunca de fijar la atención tanto del legislador como de los jueces, además de la de la doctrina, al menos respecto de la condición jurídica de los pertenecientes a las comunidades lingüísticas más consistentes y compactas del área alpina. Sin embargo, sólo recientemente, gracias a algunas relevantes y esperadas intervenciones normativas, se ha podido registrar una toma de conciencia significativa que supone un sensible progreso en la consideración de las situaciones minoritarias. El desarrollo por medio de una Ley general del art. $6 \mathrm{Cl}$ (Ley 482/1999, de 15 de diciembre de 1999, "Normas en materia de tutela de las minorías lingüísticas históricas") ha constituido el primer paso en dicha dirección, plasmando el abandono definitivo por parte de las fuerzas políticas de su posición de

* Traducción: Pedro Julio Tenorio Sánchez, Letrado del Tribunal Constitucional. Profesor Titular de Derecho Constitucional, Facultad de Derecho. UNED. 
tendencial desconocimiento respecto de las minorías lingüísticas no coincidentes con los grupos francófono y germanoparlante, respectivamente localizados en los territorios de las regiones del Valle de Aosta y el Trentino-Alto Adigio, a los que se limita con carácter exclusivo la disciplina tuteladora contenida en los estatutos especiales y correspondiente normativa de desarrollo. La modificación del estatuto especial del Trentino-Alto Adigio a fin de permitir, entre otras cosas, el reforzamiento de la tutela de situaciones minoritarias presentes en los territorios de las provincias de Trento y Bolzano (Ley constitucional $2 / 2001$ ) y la previsión de la tutela global de la minoría eslovena de Friuli-Venezia Giulia (Ley 38/2001) confirman la tendencia evolutiva de la autoridad estatal respecto de las minorías lingüísticas distintas de las llamadas minorias nacionales, en armonía con los principios formulados por los organismos internacionales y europeos en el sentido de una progresiva sensibilización de las instituciones políticas hacia las lenguas y las culturas menos difundidas, cuya salvaguardia concurre a promover el enriquecimiento espiritual de cada individuo y a la edificación de una sociedad efectivamente multicultural y plurilingüe.

A la luz de tales premisas la presente reflexión partirá por tanto de una sintética reseña de los principales documentos internacionales y regionales de los que cualquier ordenamiento democrático ya no puede prescindir, entre otras, por razones de homogeneidad, a la hora de configurar un estatuto jurídico de las minorías lingüísticas. El encuadramiento de la cuestión en los datos constitucionales y el análisis de la contribución ofrecida por la doctrina y por la jurisprudencia constitucional permitirán, a continuación, introducir al examen de los contenidos de las recientes intervenciones del legislador estatal y formular algunas reflexiones en orden a las posibles tendencias evolutivas, sin dejar de prestar atención al relevante papel de los entes territoriales - regiones y entes locales- en la tutela bien de los patrimonios lingüísticos en cuanto bienes culturales, bien de los usos públicos de las lenguas minoritarias.

2. El intento de ofrecer una reconstrucción tendencialmente unitaria y una definición de conjunto exhaustiva del concepto de "minoría" - susceptible de ser aplicado a la minoría nacional, étnica, lingüística, cultural, religiosa- ha ocupado desde el final de la Primera Guerra Mundial tanto a la comunidad internacional como a la científica, sin alcanzar sin embargo resultados satisfactorios. La falta de acuerdo en orden a la noción de minoría y a sus elementos constitutivos si, por un lado, no ha impedido en todo caso a los organismos internacionales competentes dirigir su atención a las múltiples mani- 
festaciones del fenómeno minoritario, estableciendo una serie de obligaciones a cargo de los Estados, por otro lado ha permitido especialmente a las iniciativas del Consejo de Europa situar junto al tradicional enfoque subjetivo - las minorías o los hablantes de lenguas minoritarias - un enfoque objetivo - las lenguas a preservar y valorar- respecto al cual, por lo demás, la búsqueda de una fórmula definitoria, si bien laboriosa, ha sido al fin coronada con éxito'.

En cuanto susceptibles de ser incluidas entre las minorías voluntarias, las minorías lingüísticas no resultan adecuadamente protegidas

1 El primer intento de identificación del concepto de minoría se remonta al dictamen aprobado en 1930 por el Tribunal Permanente de Justicia internacional en orden a la convención greco-búlgara de 1919. En el periodo sucesivo a la Segunda Guerra Mundial, el diferente enfoque de la comunidad internacional hacia los problemas minoritarios y la prevalente opción individualista determinaban una momentánea pérdida de interés para los intentos definitorios, hasta que en los años 70 , en el seno de la subcomisión de la ONU para la lucha contra las medidas discriminatorias y la protección de las minorías, el Prof. Capotorti, que era el presidente de la subcomisión, formulaba la célebre definición de la minoría como "...un grupo numéricamente inferior al resto de la población de un Estado, en posición no dominante, cuyos miembros - siendo ciudadanos del Estado- poseen características étnicas, religiosas, o lingüísticas que difieren de las del resto de la población y muestran, al menos implícitamente, un sentido de solidaridad orientado a preservar sus culturas, tradiciones, religiones, lenguas" (Cfr. CAPOTORTI, F.: Study on Persons Belonging to Ethnic, Religious and Linguistic Minorities, New York, 1979, § 568). La definición propuesta por Capotorti era retomada en el ámbito de los trabajos de las Naciones Unidas por el Informe Deschênes (1985) y por el Informe Eide (1993). Análogos intentos definitorios eran ensayados por el Parlamento Europeo con' respecto a la noción afín de "grupo étnico" en el proyecto de informe sobre la defensa de los derechos de los grupos étnicos establecidos en los Estados miembros (1993) y por la asamblea parlamentaria del Consejo de Europa (Recomendación 1255 de 1995). A falta de una definición oficial de minoría lingüística - a cuya investigación han contribuido de todas formas, según diferentes enfoques metodológicos, las ciencias jurídicas, sociales y lingüísticas- la doctrina indica algunos índices de reconoscibilidad de las comunidades lingüísticas minoritarias: se trata de comunidades en estado difuso, permanentes, voluntarias, generalmente privadas de personalidad jurídica, numéricamente inferiores al resto de la población, animadas por el deseo de conservar y revalorizar los propios rasgos distintivos. Cfr. Por todos, PIzzonusso, A.: Le minoranze nel diritto pubblico interno, Milán, 1967, págs. 126 ss.; Ídem, voz "Minoranze etnico-linguistiche", en Enc. Dir., XXVI, Milán, 1976, págs. 531 ss. Recientemente, la Carta europea de las lenguas regionales minoritarias (1992) ha contribuido a coronar los esfuerzos definitorios emprendidos hace mucho tiempo, identificando las lenguas regionales o minoritarias como lenguas utilizadas tradicionalmente en el territorio del Estado por ciudadanos del mismo Estado que constituyen un grupo numéricamente inferior al resto de la población y distinto por la(s) lengua(s) oficial(es) del mismo Estado, con exclusión de los dialectos y de las lenguas de los inmigrantes (art. 1). 
si no acompañan al principio de igualdad formal y de no discriminación sobre la base del factor lingüístico preceptos orientados a la realización de la igualdad sustancial y a la potenciación del patrimonio lingüístico y cultural correspondiente. El primer aspecto de la tutela, que se concreta con dicho reconocimiento - la igualdad ante la ley y la igual protección de la ley- a todos los ciudadanos, o, mejor, a todo individuo presente, en un determinado momento, en el territorio nacional $-y$, por tanto, indirectamente a los miembros de grupos minoritarios-, recibía consagración formal en la comunidad internacional con la redacción de la Carta de las Naciones Unidas (1945) y de la Declaración Universal de los derechos del hombre (1948) que habría de ser confirmada con la adopción de sucesivos acuerdos internacionales. En la misma línea el Consejo de Europa prohibía cualquier discriminación fundada, entre otras causas, en la lengua y en la pertenencia a una minoría nacional (art. 14 CEDDHH).

La previsión generalizada del principio liberal de igualdad formal y la correlativa exigencia de una tutela negativa, formulable como pretensión por parte de cualquiera - nacional o extranjero- a no recibir de los poderes públicos tratamientos irrazonablemente perjudiciales por el hecho de usar una lengua distinta de la mayoritaria/ oficial/ nacional, se conecta con el principio de la libertad de lengua, frecuentemente reconocido implícitamente tanto en el Derecho interno como en el internacional en cuanto manifestación de la prohibición expresa de no discriminación por motivos de lengua y de la igual dignidad, al menos teóricas, de todo idioma².

Desde el periodo comprendido entre los dos conflictos mundiales, los diversos instrumentos internacionales no han dejado de completar el principio de no discriminación con la indicación a los Estados de que se comprometieran activamente para eliminar o reducir las situaciones de desventaja que a menudo afectan a los pertenecientes a los grupos minoritarios. En tal sentido, no se puede dejar de entre-

2 No obstante el valor tendencialmente universal, en principio de la libertad de lengua es susceptible en concreto de sufrir erosiones y derogaciones por obra de mecanismos no fácilmente conciliables con aquél y fundamentados en prevalecientes motivaciones prácticas, además de históricas y políticas. Constituye un ejemplo de los mismos la jurisprudencia del Tribunal Federal suizo que en más de una ocasión ha dejado prevalecer el criterio territorial sobre el personal de la libre elección de lengua, favoreciendo asi a la comunidad germanoparlante, ya bastante fuerte desde el punto de vista cultural, económico y político. (Cfr. Sentencias Derungs de 1974 y Brunner de 1980). 
ver en la prudente formulación del art. 27 del Pacto internacional sobre derechos civiles y políticos de 1966 ( («las personas pertenecientes a...minorías no pueden ser privadas del derecho a....) también una pretensión de los particulares a la intervención activa del Estado para que se permita a los miembros de los grupos minoritarios "emplear su propia lengua" y "tener... su propia vida cultural". Según la línea abierta por la disposición citada pero empleando un planteamiento más abiertź mente formulado en términos positivos, la Declaración de la Asambiea General de la ONU sobre los derechos de las personas pertene:ie, Ites a las minorías nacionales o étnicas, religiosas o lingüísticas de - 992, aunque no esté dotada de la misma fuerza vinculante del Pacto in ernacional, reconocía junto al principio de la uniformidad de trata-

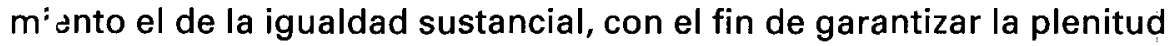
de las situaciones jurídicas subjetivas enumeradas, así como la preservación y el desarrollo de los caracteres propios de las minorías.

Además de en el marco de Naciones Unidas, el tema de la tutela positiva de las situaciones minoritarias y la garantía del derecho de las minorías a la existencia y al mantenimiento de su identidad eran profundizados en los trabajos de la Organización para el Seguridad y la Cooperación en Europa sobre la «dimensión humana». En los contenidos del Acta final de Helsinki (1975) y a continuación en las Addendas de Helsinki, los documentos con las conclusiones de las diversas reuniones (Viena, 1989; Copenhague, 1990; Ginebra, 1991) repetían el deber de los Estados de tomar las medidas legislativas, administrativas $y$ judiciales necesarias para la realización de la igualdad, en la doble acepción formal y sustancial, así como de crear las condiciones para la promoción de la identidad étnica, cultural, lingüística y religiosa de las minorías nacionales. En la misma perspectiva se sitúan algunos recientes documentos del Consejo de Europa: la Carta europea de las lenguas regionales o minoritarias (1992) y la Convención-marco para la protección de las minorías nacionales (1994) que, aun con distintos enfoques dirigidos respectivamente a las lenguas menos usadas y a los Estados signatarios, sancionan claramente el compromiso de las partes de preservar la identidad de las comunidades minoritarias a través del reconocimiento a sus miembros de un catálogo de situaciones subjetivas dirigidas a permitir el uso del idioma minoritario tanto en la vida privada como en las relaciones públicas ${ }^{3}$.

3 Cfr, sobre la Carta de las lenguas regionales y minoritarias, PETSCHEN, S.: "La Carta europea de las lenguas regionales minoritarias", en Rev. Est. Pol., n. 66, 1989, págs. 127 ss.; Albanese, F.: «Ethnic and Linguistic Minorities in Europe", en 
El reconocimiento del derecho al mantenimiento de la identidad cultural si, por una parte, presupone el derecho a la existencia del grupo en cuanto tal y la prohibición al Estado de proceder a la asimilación de los pertenecientes a la minoría, por otra parte ofrece una importante contribución a la realización del pluralismo de culturas, que constituye a su vez una de las manifestaciones más típicas e irrenunciables de los ordenamientos democráticos contemporáneas $y$ uno de los objetivos de la política comunitaria. El art. 151 del Tratado de Amsterdam (1997), en efecto, tras declarar que la Comunidad "contribuye" al pleno desarrollo de las culturas de los Estados miembros "en el respeto de sus diversidades nacionales y regionales" y "estimula" la cooperación entre los Estados (art. 151, apdos. $1 .^{\circ}$ y $2 .^{\circ}$ ), dispone que en el desarrollo de las restantes políticas diseñadas en el Tratado, la misma tiene en cuenta los aspectos culturales "en particular a fin de respetar y promover la diversidad de sus culturas" (art. 151, apdo. $4 .{ }^{\circ}$. Objetivos de análoga naturaleza encuentran consagración en el texto de la Carta de los derechos fundamentales de la Unión europea (2000), que, junto al principio de no discriminación sobre la base -entre otras circunstancias- del origen étnico, de la lengua, de la pertenencia a una minoría nacional (art. 21), dispone el respeto por parte de la Unión a la «diversidad cultural, religiosa y lingüística» (art. 22).

La general debilidad del sistema internacional de protección de las situaciones minoritarias, imputable tanto a la forma jurídica elegida para la adopción de los concretos instrumentos normativos como al establecimiento de mecanismos poco eficaces de verificación de los cumplimientos estatales, no implica automáticamente el debilitamien-

\footnotetext{
Yearbook on European Law, 1991, págs. 331 ss.; DECAUX, E.: “Minorités rationales et droits culturels", en CSCE-Bulletin, vol. I, n. 2, 1993, págs. 9 ss.; KovaCS, P.: "La protection des langes des minorités ou la nouvelle approche de la protection des minorités?», en Rev. Gén. Dr. Intern. Pub., 1993, págs. 411 ss.; DeL VeCCHIO, A. M.: "La tutela delle minoranze nei sistemi di cooperazione internazionali", en Riv. Int. Dir. Uomo, n. 3, 1994, págs. 572 ss. Sobre la Convención-marco para la protección de las minorías nacionales, cfr. BenOîT RoHmer, F.: "La Convention-cadre du Conseil de l'Europe pour la protection des minorités nationales", en Human Rights $Q$., vol. 18, n. 1, 1996, págs. 174 ss.; KLEBES, H.: «La Convention-cadre du Conseil de I'Europe pour la protection des minorités nationales", en Rev. Trim. Dr. de l'homme, n. 30, 1997, págs. 205 ss.; MITIC, M.: "Protection of National Minorities in Europe», en Rev. Int.'I. Aff., 1998, págs. 3 ss.; BARTOLE, S.: "Una Convenzione quadro per la tutela delle minoranze nazionali", en Bartole, S., OlivetTI RASON, N., y Pegoraro, L. (eds.): La tutela giuridica delle minoranze, Padova, 1999, págs. 16 ss.
} 
to de los contenidos y de los efectos jurídicos de aquellas previsiones. Antes al contrario, su elasticidad y no inmediata fuerza preceptiva pueden traducirse en un incentivo para los gobiernos nacionales, siempre que en estos esté madura la voluntad de asumir la tutela - negativa y positiva- de las minorías como valor característico para los respectivas ordenamientos.

Si la ratificación de los tratados vincula a las partes al cumplimiento de los compromisos deliberadamente asumidos y si análoga naturaleza obligatoria debe reconocerse a las prescripciones contenidas a los varios protocolos anexos a convenciones ya en vigor, más articulada se presenta la cuestión del valor jurídico de las llamadas convenciones-marco. La Convención para la protección de las minorías nacionales, por ejemplo, no predetermina de modo taxativo situaciones jurídicamente vinculantes, sino que se limita a establecer algunos principios directivos susceptibles, a su vez, de las más diversas aplicaciones en relación a las discrecionales opciones de los Estados signatarios. Se trata, pues, de un instrumento particularmente flexible, dado su contenido programático y, precisamente por esto, susceptible de adaptarse a las múltiples y diversificadas exigencias de los distintos ordenamientos. Análogamente, la Carta de las lenguas regionales o minoritarias, al indicar una serie de compromisos a ser asumidos alternativamente por parte de los Estados que se adhieran (Parte III), sin perjuicio del nivel mínimo necesario de garantía establecido en la Parte II que se aplica plenamente, tiende a salvaguardar al máximo la facultad de apreciación de las autoridades nacionales y a permitir la mejor adecuación posible de sus previsiones a las concretas realidades locales.

En el mismo sentido, la naturaleza meramente indicativa o interpretativa, aun cuando solemne, de los documentos aprobados (resoluciones, recomendaciones, declaraciones) en el seno de las distintas organizaciones internacionales no permite derivar efectos vinculantes para los Estados destinatarios, que no están obligados a sujetarse a los comportamientos recomendados.

En cualquier caso, la progresiva sensibilidad demostrada en las sedes internacionales competentes hacia el fenómeno minoritario no podía dejar completamente indiferente al legislador nacional, que en las disposiciones que abren la Ley 482/1999 hace referencia genéricamente a los principios internacionales en la materia, en los cuales declara querer inspirarse (art. 2), mientras en algunas de las más avanzadas normativas regionales tuteladoras de las lenguas minoritarias locales se contienen reenvíos más detallados a los documen- 
tos elaborados por la comunidad internacional y por el Consejo de Europa ${ }^{4}$. A la entrada en vigor en el ordenamiento italiano de la Convención europea sobre los derechos del hombre (Ley 848/1955) han seguido, más recientemente, la ratificación de la Convención-marco para la protección de las minorías nacionales (Ley 302/1997), mientras sólo ha sido firmada la Carta europea de las lenguas regionàles o minoritarias (27 de junio de 2000$)^{5}$.

3. El modelo de tutela de las minorías lingüísticas diseñado por el legislador italiano se caracterizaba, hasta época reciente, por el otorgamiento de un "status" jurídico privilegiado a las llamadas minorías nacionales - grupos francófono del Valle de Aosta, germanófono de Alto Adigio y, en menor medida, esloveno de las provincias de Trieste y Gorizia ${ }^{6}$ - y a la casi total ausencia de medidas de protección res-

4 Cfr., por ejemplo, Ley reg. de Veneto 73/1994; Ley reg. de Friuli-Venezia Giulia 15/1996 y Ley reg. de Cerdeña 26/1997.

5 Hasta ahora, la Convención-marco para la protección de las minorias nacionales ha sido ratificada por los siguientes países: Albania, Armenia, Austria, Azerbaijan, Bulgaria, Croacia, Chipre, República Checa, Dinamarca, Estonia, Finlandia, Alemania, Hungría, Irlanda, Italia, Liechtenstein, Lituania, Malta, Moldavia, Noruega, Polonia, Rumania, Rusia, San Marino, Eslovaquia, Eslovenia, España, Suecia, Suiza, Macedonia, Ucrania, Reino Unido, Bosnia-Herzegovina, Yugoslavia y ha sido firmada por Portugal, Holanda, Luxemburgo, Letonia, Islandia, Grecia, Georgia, Bélgica. La Carta europea de las lenguas regionales o minoritarias ha sido ratificada por los siguientes Estados: Armenia, Chipre, Austria, Croacia, Dinamarca, Finlandia, Alemania, Hungría, Liechtenstein, Holanda, Noruega, Eslovaquia, Eslovenia, España, Suecia, Suiza, Reino Unido, y ha sido firmada por Azerbayan, Moldavia, Ucrania, Macedonia, Rusia, Rumania, Malta, Luxemburgo, Italia, Islandia, Francia, República Checa, Chipre, Armenia (cfr. http://conventions.coe.int.). A propósito de la falta de ratificación por parte de Francia de la Carta de las lenguas regionales o minoritarias, es significativa la decisión del Consejo Constitucional (decisión 99-412 de 15 de junio de 1999) que, estimando el recurso presentado por el Jefe del Estado, consideraba no conforme a la Constitución el documento en cuestión, cuyas disposiciones contradecían los principios de la indivisibilidad de la República, de igualdad y unidad del pueblo francés así como con la proclamación del carácter oficial de la lengua francesa; para un comentario a la sentencia, cfr. Mélin-Soucramanien, F.: "La République contre Babel", en Rev. Dr. Pub., n. 4, 1999, págs. 985 ss.

6 El Estatuto del Valle de Aosta (Ley constitucional 4/1948) ha optado a favor de la minoría francófona allí residente por un sistema de bilingüismo total como consecuencia del cual las lenguas italiana y francesa son igualadas en la región y los documentos públicos pueden ser redactados en cualquiera de las dos lenguas sin necesidad de traducciones, en el acceso a la función pública el ser originario de la región o el conocimiento de la lengua francesa constituye título preferencial y en la enseñanza se dedica a las dos lenguas igual número de horas. El 
pecto de los pertenecientes a los restantes, si bien menos consistentes, grupos de diferentes lenguas de antiguo establecimiento diseminados por el territorio nacional. El distinto enfoque aparecido ya durante los trabajos preparatorios de la Carta constitucional entre islas lingüísticas y minorías étnicas y lingüísticas de los territorios fronterizos -las únicas, estas últimas, dignas de relevancia en el ámbito jurídico y político ${ }^{7}$ aunque no dejó huella en el art. $6 \mathrm{Cl}^{8}$ ha tenido consecuencias

Estatuto de Trentino-Alto Adigio (Ley constitucional 5/1948, sustituido por la Ley constitucional $1 / 1971 \mathrm{y}$, más recientemente, modificado por la Ley constitucional $2 / 2001$ ) ha optado en cambio en beneficio de la población germanófona de la región por el principio de la separación que permite el uso "disjunto" [esto es, o se usa la lengua italiana o la alemana] de las lenguas italiana y alemana y se refleja en la organización del sistema escolar en la provincia de Bolzano, en la regulación del uso de la lengua materna en las relaciones con los órganos administrativos y jurisdiccionales situados en la provincia o con competencia regional (cfr. d.P.R. $574 / 1988$ ) y en la previsión del mecanismo proporcional étnico para el acceso a la función pública del personal civil de las administraciones estatales y de los órganos judiciales de la provincia de Bolzano con base en la importancia numérica de los grupos lingüísticos italiano, alemán y ladino de la provincia según resulta de las declaraciones de pertenencia hechas en el censo oficial de la población (d.P.R. 752/1975). El Estatuto del Friuli-Venezia Giulia (Ley constitucional 1/1963) no contiene disposiciones específicamente dedicadas a la tutela de las minorías lingüísticas de la región. La condición jurídica de la minoría eslovena resulta de una normativa estratificada compuesta de acuerdos internacionales, documentos legislativos y administrativos del Estado y de la región, a los que se ha añadido últimamente la Ley estatal 38/2001 (Normas para la tutela de la minoría lingüística eslovena de la región Friuli-Venezia-Giulia), sobre la cual v. infra. $\$ 4$.

7 Cfr., al respecto, el informe publicado en Dossier Provvedimento, La tutela delle minoranze linguistiche. Normativa statale e regionale, $\mathrm{n} .121 / \mathrm{II}, \mathrm{XI}$ legislatura-marzo 1993, Camera dei deputati-Servizio Studi, págs. 19 ss.

8 Lo que en la numeración definitiva del texto constitucional sería el art. 6 , según el cual "La república tutela con normas específicas a las minorías lingüísticas", fue aprobado por la Asamblea constituyente (22 de julio de 1947) como conclusión de un animado debate que, además de llevar a cabo por primera vez un "discrimen" [distinción] entre los numerosos grupos minoritarios establecidos en nuestro país, unió el tema a la configuración de la forma de Estado. En tal sentido, el proponente - on. Codignola- sugería insertar la disposición en el título de la Constitución dedicado al ordenamiento regional [art. 108-bis: "La República garantiza el pleno y libre desarrollo, en el ámbito de la Constitución, de las minorías étnicas y lingüísticas existentes sobre el territorio del Estado (apdo. 1. ${ }^{\circ}$ )./ Los entes autónomos regionales no pueden, de ninguna forma, limitar o modificar los derechos fundamentales del ciudadano reconocidos por la presente Constitución, ni emanar normas en contradicción con la misma (apdo. $2 .^{\circ}$ )"]. A propuesta del on. Tosato, el pleno decidió al final incluir la disposición entre los Principios fundamentales de la Constitución, toda vez que la protección de las situaciones minoritarias no podía considerarse un problema ligado exclusivamente a la autonomía regional, siendo más bien una cuestión de origen general. Así era superada, por 
en los avatares del desarrollo del precepto constitucional y en el pensamiento del juez de las leyes. El Tribunal constitucional ha contribuido en efecto, con la definición y progresiva aclaración de concepto de minoría lingüística reconocida, a potenciar, en cierto sentido, en sede interpretativa, las categorías delineadas por los constituyentes. Los pronunciamientos del juez constitucional, por otra parte, han recibido impulso y, al mismo tiempo, ofrecido apoyo al comportamiento ambiguo del legislador ordinario, orientado a subrayar la posición favorable hacia las minorías lingüísticas reconocidas - como confirman las normativas esporádicamente sobreañadidas a los estatutos especiales ${ }^{9}$ - con una actitud agnóstica, cuando no manifiestamente hostil, respecto de los restantes grupos de otras lenguas, relegados al «status» de minorías lingüísticas no reconocidas. Estas últimas, distribuidas en los territorios tanto de las regiones ordinarias como de las especiales, carentes de una ley general de reconocimiento, han recibido una atención bastante modesta por parte del legislador estatal, pudiendo contar solamente con las iniciativas de los legisladores locales progresivamente sensibles a la promoción de los usos públicos de las lenguas minoritarias ${ }^{10}$, no sin traicionar en algunas ocasiones la tentación de instrumentalizar los contenidos de la tutela lingüística a prevalentes intereses de naturaleza económica. La línea de demarcación $-\mathrm{y}$ discriminación- entre grupos lingüísticos era por tanto trazada con

lo demás, la objeción del on. Ruini, cuyo proyecto de Constitución no había contemplado específicamente la tutela de las minorias, teniendo en cuenta que la afirmación del principio de igualdad para todos los ciudadanos independientemente de la raza y de la lengua (art. 2 del proyecto) habría convertido cualquier ulterior previsión en repetitiva.

9 Si se exceptúan las normativas estatales dictadas con relación a las "minorías lingüísticas reconocidas" (v.gr. art. 109 Código de procedimiento penal; art. 7 de la Ley 277/1993; art. 1, apdo. 6. ${ }^{\circ}$, letra b) punto 7 y art. 2.6 de la Ley 249/1997), o "de alguna manera reconocidas" (v.gr. art. 72 R.D. 1238/1939), o bien a las minorías lingüísticas tuteladas por los Estatutos especiales o garantizadas por formas particulares de tutela (v.gr. art. 54 el PR 315/1965; art. 35, apdo. 3 de la Ley 1213/1965; art. 3, apdo. 3 de la Ley 2/1997; art. 9, apdo. 3. ${ }^{\circ}$ de la Ley 315/1993) implícitas y modestas referencias a las comunidades lingüísticas minoritarias en general se contienen en normativas estatales sectoriales, que hacen referencia a la tutela de las características étnicas y culturales en la regulación de la radiodifusión sonora (art. 3, apdo. $10 .^{\circ}$ de la Ley 223/1990), a los grupos étnicos y lingüísticos en cuanto titulares del derecho de acceso radiotelevisivo (art. 6 de la Ley 103/1975), a la difusión de ideas fundadas en el odio racial o étnico para limitar la libertad de expresión y asociación de los ciudadanos (art. 1 decreto-Ley 122/1993), a todo comportamiento que suponga una distinción basada, entre otros factores, en el origen racial o étnico para definir el concepto de discriminación (art. 41 de la Ley 40/1998).

10 Cfr. infra $\$ 5$. 
base en una declaración formal de reconocimiento, que equivalía a identificar una determinada comunidad minoritaria y a promoverla de una condición meramente existencial a otra jurídicamente relevante, haciéndola así destinataria de formas de tutela especial, que concurrían a asegurar la igualdad sustancial y a reforzar al mismo tiempo la dimensión colectiva de la misma a través de la potenciación del sentido de solidaridad del grupo y de las garantías de los derechos lingüísticos, que se estructuran prevalentemente con base en el criterio territorial. A falta de reconocimiento, la minoría lingüística se colocaba, por así decir, en un estadio prejurídico, de mero hecho, que no le permitía beneficiarse de medidas de protección de las generales $y$ genéricas, utilizables por cualquier ciudadano o individuo, independientemente de cualquier pertenencia minoritaria, y todo lo más de intervenciones de política cultural, preferentemente confiadas a la iniciativa del legislador local.

Pronunciándose sobre el uso de la lengua eslovena ante la autoridad judicial en la provincia de Trieste, el Tribunal Constitucional deducía la atribución a la minoría eslovena de aquella provincia el "status" de minoría lingüística reconocida del cumplimiento de precisas obligaciones internacionales así como de la adopción de normas internas de rango constitucional y de actos normativos nacionales y regionales de alguna manera conectados a los compromisos internacionalmente contraídos por el Estado italiano (sentencias 28/1982 y 62/1992). Respecto de tal interpretación la doctrina argumentaba críticamente que si las minorías reconocidas eran solamente aquellas a que se referían las disposiciones de los Estatutos especiales y del Derecho internacional ${ }^{11}$, las comunidades lingüísticas minoritarias para las cuales no concurrieran los mencionados presupuestos jurídicos, por estar afectadas por avatares históricos y constitucionales distintos, no podían disfrutar en cuanto tales del reconocimiento, y el fundamento de su tutela habría por tanto de ser buscado en la regla general de art. 6 $\mathrm{Cl}$, siempre que uno no se limite a los aspectos estrictamente culturales ${ }^{12}$. Sobre la cuestión de la fuente habilitada para reconocer una

11 Cfr. PALICI DI Suni Prat, E.: In torno alle minoranze, Turín, 1997, págs. 29 ss.

12 En tal caso, el fundamento de la tutela se encontraría, más que en el art. 6, en el art. $9 \mathrm{Cl}$. Al respecto, PIzzonusso, A.: "Problemi giuridici dell'uso delle lingue in Italia (con particolare riferimento alla situazione delle minoranze linguistiche non riconosciute)", en Le Regioni, 1977, pág. 1035, y "Libertá di lingua e diritti linguistici: una rasegna comparata", ivi, 1987, págs. 1332 ss., señala la línea de demarcación entre la tutela de la lengua en cuanto factor característico de una for- 
minoría lingüística, argumentaciones más detalladas - no obstante las oscilaciones y algunos revirements respecto de la jurisprudencia constitucional- provenían de las jurisdicciones llamadas a resolver concretas controversias relativas a los usos públicos de la lengua eslovena. En este sentido se invocaba el ejercicio de la potestad legislativa de Estado a fin de garantizar la efectividad de los arts. $6 \mathrm{Cl}$ y 3 de Estatuto de Friuli-Venezia Giulia y hacer posible la predisposición de las estructuras organizativas necesarias para el goce de los derechos constitucionalmente garantizados a los componentes de la minoría lingüística ${ }^{13}$. Los desarrollos de la jurisprudencia constitucional y en particular la superación del angosto planteamiento de la tutela de las minorías lingüísticas como "materia" de competencia estatal, por un lado (sent. 312/1983), y el otorgamiento de la autonomía estatutaria a ayuntamientos y provincias (art. 4 de la Ley 142/1990), por otro, no podian ser ignorados por el juez administrativo, que precisaba el alcance y los contenidos de la posibilidad de intervención de las fuentes legislativas no estatales. Si era ya pacífica la exclusión de una reserva de ley estatal, no parecía, por otra parte, admisible que las regiones y los entes locales, en el ámbito de las respectivas atribuciones se permitieran "abierta o subrepticiamente" introducir el reconocimiento de las lenguas minoritarias, que debía ser competencia "exclusiva» de Estado ${ }^{14}$. Según ese planteamiento, en efecto, sólo una normativa estatal podía armonizar el principio fundamental del art. 6 $\mathrm{Cl}$ con los demás principios constitucionales implicados, no pudiendo por tanto en ausencia de ella deducirse automáticamente de una regulación de rango regional o reglamentario - cono la dictada por un estatuto municipal- la atribución del "status" de minoría lingüística reconocida.

4. Por fin, el legislador ordinario ha contribuido a aclarar la equivocidad de la noción y los interrogantes sobre la posible naturaleza del acto de reconocimiento de las minorias lingüisticas. Como con-

mación social o en cuanto bien cultural en la presencia o ausencia de un sentido de autoconciencia identitaria en los hablantes del idioma minoritario.

13 Cfr. Tribunal Administrativo Regional (TAR) de Friuli-Venezia Giulia, sent. 23 de septiembre de 1982, n. 187, en Le Regioni, n. 1-2, 1983, págs. 250 ss.; Cons. Stato. sez. IV, 3 de octubre de 1990, n. 730, en Foro amm., 1990, págs. 1182 ss.; Trib. Trieste, 16 de febrero de 1988, n. 821, en Cass. pen, 1990, págs. 852 ss.; Cass. pen, sez I, 3 de marzo de 1992, en Cass. pen, 1992, págs. 1797 ss.; Corte Conti, set. 1381/1983, en Riv. Corte Conti, 1984, l, págs. 368 ss.

14 Cfr. Tribunal Administrativo Regional de Friuli-Venezia Giulia de 15 de julio de 1996, n. 783, en TAR 1996, págs. 3181 ss. 
clusión de un largo y accidentado iter parlamentario comenzado en la VIII legislatura, la Ley 482/1999 es la primera "ley general» de desarrollo del art. $6 \mathrm{Cl}^{15}$, idónea para proporcionar las premisas comunes para la predisposición de un estatuto jurídico modulable por parte de los poderes locales y dirigido a todas las minorías lingüísticas expresamente enumeradas, entre las cuales se encuentran también las poblaciones minoritarias del arco alpino ya destinatarias, por las razones en su momento evidenciadas por la llamada Comisión Forti en la Asamblea constituyente, de medidas especiales de protección. Tras haber proclamado el carácter oficial del italiano y colocado entre los objetivos de la República la potenciación del patrimonio lingüístico y cultural de la lengua italiana y la promoción de la potenciación de las lenguas y culturas expresamente objeto de tutela (art. 1), la Ley en efecto compromete a la República a la tutela de la lengua y cultura de las poblaciones albanesas, catalanas, germánicas, griegas, eslovenas, croatas y de las que hablan el francés, el franco-provenzal, el friulano, el ladino, el occitano y el sardo (art. 2).

En línea con un planteamiento, que no ha desaparecido nunca, que considera oportuno ligar el tema de la identidad lingüística y cultural con el de la descentralización territorial, el art.3 hace protagonistas a las poblaciones y a las instituciones locales del procedimiento de delimitación de los ámbitos territoriales a los que aplicar las medidas de protección. Sin embargo, de manera diferente de los precedentes proyectos de ley, en lugar de la autoridad regional es ahora el consejo provincial el sujeto encargado de proveer a dicha operación,

15 Las disoluciones parlamentarias sobrevenidas determinaban, hasta la XIII Legislatura, momentos de paralización y de sucesivo reinicio en el accidentado "iter» de actuación del art. $6 \mathrm{Cl}$, no sin llegar en más de una ocasión a un estadio significativo de adelanto (textos unificados de la comisión de asuntos constitucionales de la Cámara de Diputados, XI y XII Legislaturas) cuando no incluso al umbral de la aprobación definitiva (1985 y 1991). Con base en el texto sobre el cual se habia pronunciado favorablemente la comisión de asuntos constitucionales en la XII Legislatura, la Cámara transmitía al Senado el texto aprobado en la sesión de 17 de junio de 1998 (XIII Legislatura) que, sin modificaciones, recibía el placet definitivo del Senado el 25 de noviembre de 1999, convirtiéndose en la Ley de 15 de diciembre de 1999, n. 482. Como comentarios a la misma, cfr.: BARTOLE, S.: «Le norme per la tutela delle minoranze linguistiche storiche", en Le Regioni, n. 6, 1999, págs. 1063 ss.; PALICI DI SUNI PRAT, E.: "Le legge italiana sulla tutela delle minoranze linguistiche storiche nel quadro europeon, en Dir. Pubbl. Comp. Eur., I, 2000, págs. 101 ss.; PIERGIGLI, V.: «La legge 15 dicembre 1999, n: 482 («Norme in materia di tutela delle minoranze linguistiche storichen) ovvero dell'agnosticisme al riconoscimento", en Rass. Parl., n. 3, 2000, págs. 623 ss. 
previo informe de los ayuntamientos afectados; por otra parte la iniciativa popular o de una minoría del consejo o bien -cuando ninguna de dichas condiciones concurra- el resultado favorable de la consulta de la población residente prescinde del requisito de la pertenencia individual a la identidad minoritaria, cuyo rebasamiento resulta por tanto consecuente con una opción imputable a la madurez y consciencia de los ciudadanos residentes inscritos en las listas electorales de los ayuntamientos que alojan a las minorías lingüísticas señaladas por la ley.

La atribución del status de minoría lingüística reconocida por obra de la ley general y la definición de las áreas de establecimiento minoritario por parte de los entes infraregionales satisfacen los presupuestos para la realización de los derechos lingüísticos reconocidos por el legislador. La opción prevalente por el criterio territorial tolera las excepciones dispuestas como tutela de la libre opción personal en la garantía del uso de la lengua minoritaria en la enseñanza; la facultad de emplear la lengua materna está prevista en las reuniones públicas sin perjuicio de los que no conozcan la lengua tutelada y salvo el carácter oficial de la lengua italiana; el uso del idioma minoritario está por otra parte permitido en las relaciones con la administración pública, ante la autoridad judicial y en la toponimia. Los derechos lingüísticos reconocidos comprenden la garantía del uso de la lengua minoritaria tanto como instrumento de enseñanza como en cuanto materia curricular en las escuelas maternales, elementales y secundarias inferiores, sin excluir ulteriores iniciativas para la potenciación y la investigación incluso a nivel universitario (artes. 4-6); el uso de la lengua materna en las reuniones públicas, sin perjuicio del derecho de los que no conozcan la lengua tutelada a una traducción inmediata en italiano (art. 7); la publicación en el idioma minoritario de actos oficiales del Estado, de las regiones, de los entes locales territoriales y no territoriales, sin perjuicio del exclusivo valor legal del texto redactado en lengua italiana (art. 8); el uso de la lengua minoritaria en las relaciones con la administración local y ante la autoridad judicial (art. 9), así como en las indicaciones topográficas (art. 10), mientras para la recuperación de las denominaciones, eventualmente modificadas, en su forma originaria se establece la presentación de documentación idónea (art. 11) y en el sistema de los mass media el Estado está obligado a asegurar la tutela de las minorías lingüísticas en las zonas de pertenencia, a las que las regiones interesadas pueden dirigir particular atención en el ámbito de la programación radiofónica y televisiva (art. 12). 
No obstante algunos motivos de duda detectables desde el punto de vista de la interpretación literal ${ }^{16}$ respecto del conjunto del contenido de la Ley 482/1999, no se puede sino expresar una valoración positiva, sin perjuicio de esperar a su implementación. En primer lugar, es una ley de desarrollo de un principio fundamental de la Constitución que durante mucho tiempo -incluso con la complicidad del juez constitucional- se ha aplicado de manera casi exclusiva a las comunidades minoritarias concentradas en los territorios de la frontera del arco alpino a diferencia de otras comunidades lingüísticas de antiguo establecimiento, a las cuales todo lo más se les ha permitido promover la conservación y potenciación de los respectivos idiomas en cuanto bienes culturales. En segundo lugar, se trata de una ley de principios destinados a legitimar "ex post" o bien a proporcionar el oportuno fundamento jurídico a la intervención de los poderes locales, colmando de esa manera las omisiones de algunos estatutos regionales ${ }^{17}$ y permitiendo superar, también mediante mecanismos institucionales de coordinación y propuesta (art. 3, apdo. 3), la ulterior discriminación que se deriva de la fragmentación geográfica del mismo núcleo lingüístico o de núcleos lingüísticos afines, como en los casos emblemáticos de los eslovenos de Friuli-Venecia Giulia y de los ladinos, tratados de modo distinto según la provincia de residencia.

Por otra parte, la potenciación de las lenguas y culturas tuteladas incluso más allá de los confines nacionales en los territorios en que están difundidas y con la condición de reciprocidad (art. 19) es prueba del desarrollo de un principio ya sancionado por el Consejo de Europa (art, 18, apdo. $2 .^{\circ}$ de la Convención-marco para la protec-

16 Por ejemplo, en la Ley 482 ha desaparecido la mención, entre las comunidades minoritarias merecedoras de tutela, de las poblaciones gitanas - a las que por lo demás se han referido variadas iniciativas regionales-, y por otra parte no se puede dejar de notar la ambigua distinción entre las "poblaciones..." y "los parlantes...", [tal y como se expresa la Ley 482] que casi quiere postular una especie de jerarquía entre formaciones sociales que se distinguen por caracteres étnicolingüísticos propios, por una parte, e idiomas minoritarios relevantes esencialmente desde el punto de vista lingüístico-cultural, por otra, que no parece encontrar un fundamento jurídico razonable ni, mucho menos, legitimidad en los estudios sociolingüisticos.

17 Los Estatutos de Puglia, Sicilia y Cerdeña nỏ contienen referencias a las minorias lingüísticas establecidas en los respectivos territorios regionales. Además de en los Estatutos especiales del Valle de Aosta y de Trentino-Alto Adige; existen disposiciones en materia de tutela de las minorías lingüísticas en los Estatutos de Piamonte (art. 7), Veneto (art. 2), Molise (art. 4), Calabria [art. 56, letra r)]. 
ción de las minorías nacionales) que reconoce en la promoción transfronteriza e interregional y en la estipulación de convenios con Estados extranjeros en que están instaladas comunidades de lengua italiana el instrumento más idóneo para reforzar los vínculos comunes y para preservar las respectivas identidades lingüísticas y culturales del riesgo de la asimilación a las culturas mayoritarias (art, 19 apdo. $2 .^{\circ}$ ).

Si se exceptúa la expresa consagración de las obligaciones gubernamentales de adoptar en el plazo de seis meses las medidas reglamentarias de desarrollo, oídas las regiones interesadas (art. 17) y de informar anualmente al Parlamento sobre el estado de cumplimiento de los informes de cooperación con otros países (art. 19 apdo. 3 ), la ley se abstiene de fijar plazos para la activación de los procedimientos preliminares descritos por el art. 3 y de prever mecanismos de carácter sancionatorio-sustitutivo por parte del Estado en caso de inercias o retrasos de las autoridades municipales y provinciales. Superada la actitud de indiferencia y agnosticismo poco compatible con un ordenamiento democrático y pluralista, el legislador estatal ha demostrado incorporar no solamente la directiva del art. $6 \mathrm{Cl}$, sino también los preceptos constitucionales conectados con ella de diferentes formas (arts. 2, 3, 5, 9, 21), reenviando a los órganos gubernamentales y ministeriales, por una parte, y a los niveles de autonomía más próximos a los ciudadanos, por otra, el cometido de completar la base normativa así diseñada.

La inclusión de las "poblaciones...eslovenas" entre los beneficiarios de las medidas de protección concedidas a las minorías lingüísticas históricas por la Ley 482/1999 (art. 2) si de alguna manera habría debido ya de por sí cooperar a atenuar el tratamiento diverso que se deriva de la fragmentación geográfica de dicho núcleo lingüístico en los territorios de las provincias de Trieste, Gorizia y Udine, no ha impedido en todo caso la continuación de las iniciativas orientadas específicamente a los grupos eslavófonos de la región, a fin de llegar a una tutela orgánica y global. En esa línea se coloca la Ley 38/2001 que, unificando diversas propuestas presentadas en el curso de la XIII legislatura ${ }^{18}$, reconoce a la minoría eslovena establecida en las citadas provincias de la región, a las que se aplican las medidas previstas por

18 Cfr. proyecto de Ley A.S. 2750; proposición de Ley A.C. 3826; proposición de Ley A.C. 3730; proposición de Ley A.C. 3935; proyecto de Ley A.S. 4735 que. unificando los proyectos de ley números 229,3730 y 3935 , era aprobado por la Cámara el 12 de julio de 2000 y transmitido al Senado, donde el 14 de febrero de 2001 recibía la aprobación definitiva. 
la Ley $482 / 1999$, salvo lo expresamente dispuesto por la Ley 38/200119. Además de la Ley 482/1999, se invocan los arts. 2,36Cl, el artículo 3 del estatuto regional, así como los principios de las 'convención-marco para la protección de las minorías nacionales' y de la 'carta europea de las lenguas regionales o minoritarias' en cuanto principios inspiradores (art. 2). Dentro de las áreas territoriales de establecimiento tradicional de la minoría, que se establecerán en virtud de Decreto del Presidente de la República sobre la base de un esquema elaborado por un Comité institucional paritario [formado por un número igual de representantes del Estado y de las Regiones] (art.3) y a instancia de al menos el $15 \%$ de los ciudadanos inscritos o a propuesta de un tercio de los consejeros interesados (art. 4), se introducen garantías en materia de onomástica y denominaciones en la lengua minoritaria (art. 7), así como en la toponimia y en los anuncios o rótulos de negocios o establecimientos públicos (art.10); se asegura la facultad de usar la lengua eslovena en las relaciones con las administraciones públicas, incluyendo a las autoridades judiciales locales, a los concesionarios de servicios de interés público, así como en las reuniones de los órganos electivos y excluyendo las relaciones con las Fuerzas armadas y de Policía (arts. 8-9) ${ }^{20}$. Disposiciones ulteriores garantizan el derecho a la

19 Hasta la entrada en vigor de la Ley $38 / 2001$ era distinto el régimen jurídico de las minorías eslovenas distribuidas en los territorios de las provincias de Trieste, Gorizia y Udine. Si, en efecto, la comunidad establecida en la capital de la región era considerada, de acuerdo con la jurisprudencia constitucional, «minoría lingüística reconocida» en cuanto destinataria de medidas de protección previstas por acuerdos internacionales y normas de rango constitucional, al grupo homólogo establecido en el territorio de la provincia de Gorizia se referían sólo las normas contenidas en la legislación estatal en materia de enseñanza en la lengua eslovena, que por lo demás encuentran aplicación por otra parte en las escuelas eslovenas de la provincia de Trieste (Ley 1012/1961), mientras los eslovenos de la provincia de Udine quedaban privados de consideración alguna por parte del legislador estatal.

20 Tal garantía, que se articula por otra parte en el derecho a recibir respuesta en lengua eslovena, opera tanto en las comunicaciones verbales como en la correspondencia con las Administraciones públicas y en las intervenciones tanto orales como escritas internas a los órganos electivos, con la obligación de proveer a la traducción en lengua italiana de los documentos escritos en esloveno, mientras el bilingüismo italiano-esloveno está permitido en las relaciones entre órganos públicos situados en los territorios previamente establecidos [Ayuntamientos a determinar de acuerdo con lo establecido en la Ley 38/2001] de acuerdo con las modalidades reguladas en el art. 4. A fin de hacer efectivas aquellas medidas se obliga a las Administraciones a proveer a la adecuación de sus propios órganos, del personal de la organización interna; y a los entes locales se encomienda la modificación de los respectivos Estatutos de autonomía para hacerlos conformes a las sobrevenidas disposiciones de la Ley $38 / 2001$. 
educación en lengua eslovena en las escuelas públicas de las provincias de Trieste y Gorizia con reenvío a la Ley 1012/1961 (art. 11), mientras la garantía de tal derecho en las escuelas de los ayuntamientos de la provincia de Udine constituye objeto de regulación separada (art. 12), por la razón de que en aquella área la recuperación de la identidad eslovena necesita instrumentos parcialmente diferenciados y más apropiados a causa del proceso de asimilación y de la distinta historia lingüística, cultural y administrativa. El apoyo de la región a iniciativas culturales, artísticas deportivas, recreativas, cientificas, educativas, informativas $y$ editoriales desarrolladas por las instituciones representativas de la minoría eslovena (art. 16), las iniciativas del gobierno para favorecer el desarrollo de las relaciones culturales con la República de Eslovenia y entre las poblaciones fronterizas (art. 17), la transferencia a la región de determinados inmuebles para el desarrollo de actividades culturales y científicas en lengua eslovena (art. 19), la tutela del patrimonio histórico y artístico y de los intereses sociales, económicos y ambientales en los territorios de los ayuntamientos determinados a tales efectos (arts. 20-21) constituyen los objetivos más significativos asumidos por el legislador estatal para la tutela y potenciación de la identidad cultural de la minoría lingüística eslovena. Finalmente, se establece la obligación del legislador estatal de favorecer la representación parlamentaria de candidatos pertenecientes a la minoría eslovena (art. 26) y se establece la extensión de los derechos reconocidos por la ley a las asociaciones miembros de las confederaciones sindicales más representativas en el ámbito nacional, a las organizaciones sindicales y de grupos o categorías que desenvuelven su actividad prevalentemente en lengua eslovena, y sean representativas, en determinados ayuntamientos, de dicha minoría (art. 22). En las disposiciones finales, la ley confirma la vigencia de las medidas de tutela adoptadas como consecuencia del Memorándum de Londres de 1953 y del tratado de Osimo de 1975 sin excluir la aplicabilidad a la minoría eslovena de la región de las disposiciones eventualmente más favorables derivadas de la legislación nacional (art. 28).

El gobierno ha desarrollado el art. 17 de la Ley 482/1999, en espera de la completa eficacia de las correspondientes disposiciones de la Ley 38/2001, con el decreto del Presidente de la República 345/200121

21 El decreto del Presidente de la República de 2 de mayo de 2001, n. 345 (Reglamento de ejecución de la Ley de 15 de diciembre de 1999, n. 482, relativo a normas de tutela de las minorías lingüísticas históricas) está publicado en G.U. (Gazetta Ufficiale), Serie Generale, 13 settembre 2001, n. 213. 
que tras establecer las modalidades para la delimitación de los ámbitos territoriales a los que aplicar las medidas de tutela (art. 1), efectúa una serie de reenvíos a los órganos estatales, a las instituciones de enseñanza y a los entes locales respectivamente para asegurar la enseñanza de la lengua minoritaria en las escuelas maternales, elementales y secundarias de primer grado eventualmente estableciendo una fase de experimentación didáctica (art.2) para favorecer las actividades de investigación,formación, actualización profesional y educación permanente (art. 3), para definir las modalidades relativas al empleo de las lenguas "admitidas a tutela" en los órganos electivos de los entes locales y en los órganos de las administraciones públicas (arts. 4 y 6).

Confirmando la progresiva toma de conciencia del legislador italiano de las problemáticas relacionadas con la tutela de las minorías no se puede omitir mencionar, en fin, la entrada en vigor de dos leyes constitucionales. La Ley constitucional 1/1999 de revisión de los arts. $121,122,123$ y $126 \mathrm{Cl}$, si bien introduciendo un procedimiento complejo de aprobación de los Estatutos regionales, permite ampliar la autonomía estatutaria de las regiones ordinarias que, también a la luz de la normativa aludida [Ley 482/99] de desarrollo del art. $6 \mathrm{Cl}$, podría permitir a las regiones en el futuro próximo precisar mejor o introducir "ex novo" disposiciones de principios en relación con la tutela de las respectivas minorias lingüisticas. La Ley constitucional 2/2001 (Disposiciones relativas a la elección directa de los Presidentes de las Regiones de Estatuto especial y de las Provincias autónomas de Trenzo y de Bolazo) de reforma de los Estatutos especiales es importante desde la perspectiva de este trabajo, sobre todo por la modificación aportada al Estatuto de Trentino-Alto Adigio y a la disciplina de las situaciones minoritarias en la región. En primer lugar, en efecto, se ha atenuado la disparidad de tratamiento entre los grupos lingüísticos ladinos respectivamente establecidos en las provincias de Bolzano y Trento vigente conforme al Estatuto anterior (decreto del Presidente de la República 670/1972): con la revisión de 2001, se ha incorporado la inclinación que se había manifestado hacía tiempo en el sentido de asegurar al territorio coincidente con el de los ayuntamientos expresamente enumerados en que se halla establecido el grupo lingüístico ladino-dolomítico de Fassa un escaño en el consejo provincial de Trento (art. 48, apdo. 3$)^{22}$. Por otra parte, desde el punto de vista de la potenciación

22 Según el art. 62 del Estatuto (d.P.R. 670/1972), la representación del grupo lingüístico ladino estaba garantizada en los consejos regionales y provinciales de Bolzano y en la composición de los órganos colegiados de los entes públicos 
del régimen jurídico de la tutela no solamente de la comunidad ladina sino también de la comunidad germanófona de la provincia de Trento, la reforma del Estatuto especial ha reconocido a las poblaciones ladina, mochena y cimbra de los municipios expresamente enumerados de la provincia el «derecho a la potenciación de las propias iniciativas y actividades culturales, de prensa y recreativas, así como al respeto de la [toponimia] y de las tradiciones de las mismas poblaciones", añadiendo la garantía de la enseñanza de la lengua y cultura alemana y ladina en las escuelas de los ayuntamientos de provincia en que dichas lenguas sean habladas (nueva redacción del art. 102 del Estatuto $)^{23}$. La provincia de Trento garantiza destinar financiación a fin de asegurar la tutela y el desarrollo cultural, social y económico de las poblaciones ladina, mochena y cimbra, teniendo en cuenta la entidad y necesidades de ellas (texto modificado del art. 15 del Estatuto). Igualmente significativa es la extensión de la facultad —primero reconocida tan sólo al grupo lingüístico ladino de la provincia de Bolzano- de recurrir ante el Tribunal de justicia administrativa de Trento los actos administrativos y las resoluciones de los ayuntamientos, respectivamente procedentes de los consejeros regionales o provinciales y también -en el segundo caso- de los concejales previa solicitud por parte de un quinto del pleno del Ayuntamiento cuando aquellas medidas resulten lesivas del principio de paridad entre los

locales de la misma provincia. Con la reforma de 2001, el art. 62 del Estatuto fue sustituido («Las normas sobre la composición de los órganos colegiados de los entes públicos locales en la provincia de Bolzano garantizan la representación del grupo lingüístico ladino"; por otra parte el nuevo texto del art. 48 del Estatuto, tras establecer la garantía de representación del grupo lingüístico ladino en el consejo provincial de Bolzano (apdo. $2 .^{\circ}$ ) añadió en el apdo. $3 .^{\circ}$ la asignación de un puesto en el consejo provincial de Trento en garantía del grupo ladino-fassano [grupo ladino de la provincia de Trento, que vive en el territorio del valle de Fassa]. En fin, en beneficio del grupo lingüístico ladino en la región, se introdujo la garantía de representación en la junta regional incluso excepcionando el principio de representación proporcional (añadido al texto del art. $36.3 .^{\circ} \mathrm{co}$. Estatuto).

23 Antes de la revisión estatutaria del 2001, como tutela de las poblaciones ladina, moquena y cimbra de la provincia de Trento, intervino, como normativa de ejecución del Estatuto, el d.P.R. 592/1993, modificado por el d.P.R. 321/1997. El Estatuto (d.P.R. 670/1972) se limitaba a prever, como tutela de los ladinos establecidos en el territorio de la provincia de Trento, la garantía de la enseñanza de la lengua y cultura ladinas en las escuelas de los ayuntamientos de la provincia en que el idioma es hablado (art. 102, apdo. $2^{\circ}$ ), y, más en general, como tutela de las poblaciones ladinas, el derecho a la potenciación de las propias iniciativas $y$ actividades culturales, de prensa y recreativas, al respeto de la toponimia y de las tradiciones (art. 102, apdo. $2 .^{\circ}$ ). 
ciudadanos de lengua italiana, ladina, mochina y cimbra residentes en la provincia de Trento (art. 92, apdo. último del Estatuto).

5. La Ley $482 / 1999$ se inscribe, además de en la línea de los principios establecidos por los organismos europeos e internacionales, en el contexto de las iniciativas legislativas regionales preparadas sobre todo en los años 80 y orientadas no sólo a la salvaguardia de los patrimonios lingüísticos regionales, sino también a la regulación de determinados usos públicos de los idiomas minoritarios en las respectivas áreas de establecimiento. Precisamente respecto de las relaciones entre la sobrevenida ley general de principios y la existente normativa regional, se precisa que respecto de las regiones de Derecho especial se mantienen las disposiciones en vigor, salvada la posibilidad de extender las medidas más favorables de la ley general mediante decretos de desarrollo estatutario (art. 18), mientras para las regiones ordinarias el Parlamento ha salvado las disposiciones regionales vigentes que hayan introducido un régimen de mayor garantía para las minorías lingüísticas y ha dispuesto la adecuación de la legislación regional a los principios de la Ley de qua [la Ley 482/1999] en las materias de la competencia de ellas (art. 13).

La desaparición de una presunta reserva de ley estatal en "materia" de tutela de las minorías lingüísticas (STC 312/1983), que ha estado en el origen de los reenvíos reglamentarios de leyes regionales consiguientemente empequeñecidas en los objetivos y en los contenidos ${ }^{24}$ y la interpretación del término "República" del art. $6 \mathrm{Cl}$ como sinónimo de Estado-ordenamiento imprimían una aceleración al ejercicio de

24 Nos referimos, en particular, al proyecto aprobado el 28 de julio de 1977 (Tutela del patrimonio histórico y cultural de las minorías étnico-lingüísticas del Molise) que tras el reenvío al Gobierno no fue desarrollado, y al proyecto aprobado el 19 de mayo de 1977 (Tutela y potenciación del patrimonio lingüístico y cultural del Piamonte) que tras las observaciones gubernamentales sería modificado y promulgado como Ley regional del Piamonte 30/1979. Como comentario de tales reenvíos, cfr. INGICCO, R.: "Minoranze linguistiche: due iniziative rinviate dal Governo», en Le Regioni, 1977, págs. 971 ss.; Ídem: "La legge regionale piemontese sulla tutela del patrimonio linguistico e culturale», ivi, 1980, págs. 7 ss. Más recientemente, por motivos de invasión de la esfera de competencia estatal en materia de enseñanza, era impugnada por el gobierno ante el Tribunal Constitucional, que estimó las observaciones gubernamentales (sent. 290/1994), una iniciativa legislativa de la región de Cerdeña (Tutela y potenciación de la cultura y de la lengua de Cerdeña); sobre tal cuestión, cfr. las observaciones críticas de MURGIA, C.: "La competenza integrativo-attuativa della Regione sarda in materia di programmi scolastici», en Riv. Giur. Sarda, 1995, págs. 512-513. 
la potestad legislativa de las regiones - tanto de Estatuto ordinario como de Estatuto especial- que no podía luego aceptar ser relegada dentro de los ámbitos estrechos - si bien no susceptibles de ser ignorados- de la protección de los patrimonios lingüísticos y culturales locales. Los entes regionales reivindican así la competencia para regular determinados usos públicos de los idiomas minoritarios en las respectivas áreas de establecimiento. Por otra parte, tanto la reforma de las autonomías locales y el otorgamiento de potestad estatutaria a municipios y provincias (Ley 142/1990), como la reconducción a la potestad exclusiva de las regiones de Derecho especial de la regulación relativa al ordenamiento de los entes locales (Ley constitucional 2/1993), contribuían a impulsar la evolución de la normativa en la dirección indicada.

En este sentido, las intervenciones más recientes del legislador regional se ocupan, entre otras cosas, de la regulación de las iniciativas didácticas, de la promoción cultural y de la información local, de la garantía del uso de la lengua minoritaria en las relaciones de los ciudadanos con la Administación local y en el interior de las administraciones mismas, en las reuniones de los órganos de la región y de los entes subregionales en las áreas de establecimiento histórico de la población minoritaria, en la toponimia 25 , hasta la previsión de garantías de representación de las comunidades alófonas expresamente señaladas en las instituciones políticas locales y en la administración pública, tal y como se establece en tutela de la minoría ladina ante los órganos colegiados de los entes públicos locales de la provincia de Bolzano (decreto del Presidente del Consejo Regional de 29 de enero de 1987, n. 2/L, que lo establece sobre la base del art. 62 del estatuto de Trento-Alto Adigio) así como en tutela de la minoría walser del valle de Aosta, respecto de la cual el legislador regional ha dispuesto, para el caso de que se den ciertas condiciones, la reserva de un escaño en el consejo regional (Ley regional 3/1993). Por otra parte, el legislador regional compromete cada vez más frecuentemente a la administración local en la conservación y desarrollo de la identidad étnica, cultural e histórica de las poblaciones alófonas y de la comunidad regional en general (v. gr. art. 1 de la Ley regional de Friuli-Venezia Giulia 15/1996 y art. 1 de la Ley regional de Cerdeña 26/1997). La exaltación

25 En tal sentido, cfr. por ejemplo: Ley reg. de Veneto 73/1994; Ley reg. del Molise 15/1997; Ley reg. de Cerdeña 26/1997; Ley reg. de Piamonte 37/1997; Ley regional de Basilicata 40/1998; Ley reg. de Friuli-Venezia Giulia 15/1996, modificada por la Ley reg. 13/1998. 
de la identidad cultural minoritaria encuentra realización en una serie de intervenciones que afectan de diversa manera al territorio - del urbanismo a la arquitectura de los centros históricos, de la tutela del paisaje a la regulación del turismo y a la producción artesanal- y que concurren a potenciar los aspectos diferenciadores propios de las comunidades lingüisticas minoritarias, además de favorecer el crecimiento espiritual de los componentes de la colectividad regional en su conjunto ${ }^{26}$.

El redescubrimiento de la identidad minoritaria constituye no solamente uno de los datos más significativos en la evolución de la normativa regional sino también uno de los elementos recurrentes con motivo de la formulación de los estatutos municipales y provinciales, iniciándose así un enfoque renovado por parte del legislador respecto de la definición de las políticas minoritarias, que se propone fundamentarse en las peculiaridades socio-lingüísticas-culturales compartidas por los pertenecientes a determinadas comunidades para introducir un régimen jurídico orientado a su protección y potenciación dentro de ámbitos geográficos predeterminados. A la tutela de los. patrimonios lingüísticos y culturales así como a la potenciación de las actividades tradicionales se refieren, en efecto, en el marco de la autonomía municipal y provincial los estatutos de los entes locales de las regiones ordinarias y especiales, respectivamente sobre la base de los principios establecidos por el texto único sobre las autonomías locales (decreto legislativo $267 / 2000$, que ha sustituido a la Ley $142 / 1990$ ) y por la Ley constitucional $2 / 1993$, que ha reformado los estatutos especiales permitiendo desvincular el ejercicio de la potestad legislativa -exclusiva y ya no concurrente- en materia de ordenación de los entes locales del respeto a los principios fundamentales recogidos en eventuales leyes-marco estatales ${ }^{27}$. En los territorios de los ayunta-

26 Cfr., por ejemplo, la legislación sobre los parques regionales de las regiones de Veneto (Leyes $12 / 1990$ y $21 / 1990$ ) y Basilicata (Leyes $3 / 1986$ y 28/1994); la legislación sobre los centros históricos de la región de Cerdeña (Ley 29/1998) y de la provincia de Trento (Ley prov. 1/1993); la regulación de las actividades económicas en las áreas de montaña de las regiones de Veneto (Leyes 29/1983 y 2/1994), Malise (Ley 29/1999), Basilicata (Leyes 22/1994, 31/1994 y 53/1995), Calabria (Ley 4/1999), Piamonte (Ley 16/1999) y de la provincia de Trento (Ley prov. 17/1998).

27 Hasta 1993 las regiones de Estatuto Especial debian respetar los principios de las leyes-marco estatales en materia de ordenamiento de los entes locales; tras la Ley constitucional 2/1993, que ha reformado en este aspecto los Estatutos Especiales, dichas regiones pueden aprobar leyes sobre esa materia sin sujetarse a las leyes-marco del Estado. 
mientos de la provincia de Bolzano sobre la base de las disposiciones contenidas en el estatuto regional, pero también en los ayuntamientos de las regiones Friuli-Venezia Giulia, Valle de Aosta, Cerdeña, Sicilia, así cono Molise y Calabria los estatutos colocan a menudo al lado de la tutela confiada a la salvaguardia de los patrimonios lingüisticos minoritarios como bienes culturales, la garantía de los usos públicos de los idiomas minoritarios (uso de la lengua minoritaria en la enseñanza, en las señales de las calles y toponimia, en la administración local y en las relaciones con los administrados) y de la determinación de las dependencias de las administraciones locales ${ }^{28}$. Por otra parte, posteriormente el reglamento de desarrollo de la Ley 482/1999 (arts. 4 y 6 d.P.R. 345/2001) ha llamado la atención del legislador local hacia la reglamentación de los usos públicos de las lenguas minoritarias en los lugares de asentamiento histórico de los grupos minoritarios previamente establecidos, permitiendo pronosticar un incremento del grado de tutela existente o bien el inicio de un proceso de sensibilización para las instancias minoritarias anteriormente ignoradas a través de la evolución de la normativa estatutaria y reglamentaria de los entes locales.

6. El mayor activismo demostrado en los últimos años por el legislador tanto estatal como local hacia la protección de las minorias lingüísticas hasta época reciente ignoradas o débilmente protegidas si, por una parte, se inscribe en el trend que resulta de las iniciativas del Consejo de Europa y de la difundida orientación de los Estados de regular mediante tratados bilaterales o multilaterales las situaciones minoritarias de zonas fronterizas potenciando también los instrumentos de la cooperación transfronteriza ${ }^{29}$ por otro lado no puede sino

28 Sobre la regulación de los usos públicos de las lenguas minoritarias en los Estatutos de los entes locales, cfr. PAJERO, D.: "Minoranze linguistiche e governo locale nel Friuli-Venezia Giulia", en Bartole, S., OLIVETti Rason, N., y PEgoRAZO, L. (eds.): La tutela giuridica, cit., págs, 225 ss. Permítasenos por otra parte remitirnos a PIERGIGLI, V.: Lingue minoritarie e identitá culturali, Milano, 2001, págs. 476 ss.

29 Sobre la regulación de las situaciones minoritarias fronterizas mediante acuerdos entre Estados, cfr., por ejemplo, entre los instrumentos más recientes adoptados por el gobierno italiano el "Memorandum" de entendimiento italocroata-esloveno de 1992, al cual ha seguido el tratado entre Italia y Croacia de 1996 (ratificado por Italia con Ley 129/1998) para la regulación de la condición de la minoría italiana en Croacia y de la minoría croata en Molise, sobre el cual cfr. RonzirTI, N.: "ll trattato tra Italia e Croazia sulle minoranze», en Riv. Dir. Internaz., n. 3, 1997, págs. 684 ss. 
hacer reflexionar sobre las eventuales repercusiones que la introducción de un régimen derogatorio y especial, como el destinado a la protección de las minorías lingüísticas, es susceptible de producir respecto de la restante población, que corre el riesgo de venirse a encontrar, a su vez y paradójicamente, en una situación de desventaja, sin olvidar las consecuencias de naturaleza financiera que tales ir.tervenciones inevitablemente imponen en medida más o menos considerable. Si la garantía de determinados usos lingüísticos está ordenada a la salvaguardia de la identidad cultural minoritaria conforme a los principios de un Estado democrático que se compromete a promover el pluralismo en todas sus acepciones, comprendido el lingüístico y cultural, la persecución de tal objetivo no debe tener lugar de manera que perjudique irrazonablemente los derechos de los demás ciudadanos, siendo necesaria una delicada obra de ponderación entre las posiciones jurídicas de la minoría y de la mayoría que evite formas de discriminación a contrario - esto es de miembros del grupo mayoritario y en cualquier caso de los no pertenecientes a comunidades diferenciadas sobre la base del factor lingüístico- y asegure efectivamente la pacífica convivencia social. La duda se presenta, por ejemplo, cuando el ordenamiento prevea el mecanismo de las cuotas reservadas a efectos de la selección de la representación política y en la composición de los órganos o cargos públicos, en el ámbito estatal o en el descentralizado, como en los supuestos previstos por el estatuto del Trentino-Alto Adigio ${ }^{30}$. En tales hipótesis, las derogaciones a los criterios generales de la libre concurrencia entre las fuerzas políticas y del concurso público se conciben, en aplicación del principio de igualdad sustancial, a fines de garantía y eventualmente a título de compensación por los perjuicios infringidos por la historia a determinados grupos lingüísticos ${ }^{31}$.

Por otra parte, además de los problemas de compatibilidad con los derechos de los miembros del grupo mayoritario, las referidas soluciones son susceptibles de entrar en contradicción - desplazando la cuestión al ámbito de los principios de la Unión Europea- con las libertades reconocidas por el Tratado. Al respecto, ha de señalarse que no le han faltado ocasiones al Tribunal de Justicia para decidir la conformidad o disconformidad con las normas comunitarias $-\mathrm{y}$ concre-

30 Cfr. supra lo indicado en las notas 6 y 21.

31 Así, por ejemplo, en Alto Adigio el Estatuto de la región ha introducido medidas de tutela de la minoría alemana precisamente para compensarla de las violaciones padecidas durante el fascismo. 
tamente con las disposiciones relativas a la libertad de circulación y residencia de los ciudadanos comunitarios en los Estados miembros de la Unión Europea y a la libertad de circulación de los trabajadoresde figuras concebidas por la normativa nacional italiana en garantía de los ciudadanos alemanes de la provincia de Bolzano ${ }^{32}$.

En relación con la experiencia italiana, en particular, la progresiva conciencia del legislador estatal y regional hacia el fenómeno minoritario alimenta a veces la sospecha de una instrumentalización de los objetivos de autonomía cultural a la consecución de un grado mayor de autonomía política. En efecto, a menudo $-\mathrm{y}$ no solamente en Italia- los representantes regionales o de los entes locales proponen solicitudes al Estado central de mayor autonomía cultural $-y$ por tanto solicitudes de financiación estatal para satisfacer el mantenimiento de presuntas peculiaridades históricas, étnicas, lingüisticasque en realidad esconden pretensiones de autonomía política cuando no incluso separatistas. O bien, más modestamente, legisladores locales a veces usan las presuntas peculiaridades étnicas de una cierta parte de la población local para incentivar el consenso del electorado local. Parece en efecto difícil contestar el dato ampliamente verificable en la revolución de las relaciones centro-periferia de la progresiva revitalización de las instancias autonomistas y de las culturas locales, entre las cuales merecen una particular atención especialmente las marcadas por el (re)descubrimiento de reales o presuntos factores de diferenciación lingüistico-cultural. Independientemente de la especialidad o no de la autonomía conferida a las regiones, el legislador local no siempre ha sabido sustraerse a la tentación de condicionar el fin de la tutela de las minorías lingüísticas a la conservación de estructuras organizativas consolidadas, que encuentran las principales modalidades de manifestación en la disciplina de las actividades económicas,

32 Nos referimos, respectivamente, al Tribunal de Justicia de las Comunidades Europeas, sent. De 24 de noviembre de 1998, causa C-274/96, críticamente comentada por PALICI DI SUNI PRAT, E.: "L'uso della lingua materna tra tutela delle minoranze e paritá di trattamento nel diritto comunitarion, en Dir. Pubbl. Comp. Eur., n. 1, 1999, págs. 171 ss. y sent. De 16 de junio de 2000, causa C-281/98, comentada por PALERMO, F.: "Diritto comunitario e tutela delle minoranze: alla ricerca di un punto di equilibrio", ivi, n. 2, 2000, págs. 969 ss. Sobre la compatibilidad del llamado "patentino" [pequeño carné] previsto por la normativa de desarrollo del Estatuto de Trentino-Alto Adige con el principio comunitario de la libertad de circulación de los trabajadores en la UE, cfr., además, TELCHINI, I.: «Problemi in ordine all'uso della lingua in Alto Adige nei rapporti fra privati e pubblici poterin, en Studi in onore di G.M. Ubertazzi, Jus., 1999, especte. P. 528 ss. 
del turismo, de las intervenciones sobre el territorio. Es decir, los legisladores regionales, a menudo, han empleado la polémica de tutela de las minorías como instrumento para lograr otros fines: el reforzamiento de la autonomía política o el crecimiento de la economía local ${ }^{33}$.

La tutela y la potenciación de los idiomas minoritarios y de las situaciones subjetivas de los correspondientes hablantes deberían pues ser aseguradas en medida proporcional a las efectivas necesidades, teniendo al mismo tiempo presente el hecho de que una política de intervención positiva, y no fundada exclusivamente sobre el principio de no discriminación sobre la base del factor lingüístico, contribuye al enriquecimiento de una determinada nación y de la humanidad entera.

33 Cfr. BARTOLE, S.: «Le regioni alla ricerca della loro identitá culturale e storica: tentativi più o meno convinti di trovare una legittimazione etnica", en BARTOLE, S. (ed.): Le regioni alla ricerca della loro identitá culturale e storica, Milán, 1999, págs. 1 ss. 